\title{
Symptomatic migration of a Kirschner wire into the spinal canal without spinal cord injury: case report
}

\author{
Ljubodrag Minić, MD, ${ }^{1}$ Milan Lepić, MD, ${ }^{1}$ Nenad Novaković, MD, ${ }^{1}$ and \\ Stefan Mandić-Rajčević, MD, PhD²
}

\begin{abstract}
'Department of Neurosurgery, Military Medical Academy, Belgrade, Serbia; and 2Department of Health Sciences of the University of Milan, International Centre for Rural Health of the University Hospital San Paolo, and Laboratory for Analytical Toxicology and Metabolomics, Milano, Italy
\end{abstract}

\begin{abstract}
The migration of Kirschner wires (K-wires) is a rare but significant complication of osteosynthesis interventions, and numerous cases of wire migrations have been reported in the literature. Nevertheless, migration into the spinal canal is very rare, with only 10 cases reported thus far. The authors present a case of K-wire migration into the spinal canal, together with a review of the relevant literature.

A 30 -year-old male who had suffered a right clavicle fracture in a motorcycle accident was treated with $2 \mathrm{~K}$-wires. Four months after the initial fixation, while he was lifting his child, he experienced short-term pain in his back, numbness in all 4 extremities, followed by a spontaneous decrease in numbness affecting only the ulnar nerve dermatomes bilaterally, and a persistent headache. No urinary incontinence was present.

Simple radiography studies of the cervical spine revealed a wire in the spinal canal, penetrating the T-2 foramen and reaching the contralateral foramen of the same vertebra. Computerized tomography showed the wire positioned in front of the spinal cord. Surgery for wire extraction was performed with the patient under general anesthesia, and he experienced relief of the symptoms immediately after surgery.

This case is unique because the wire caused no damage to the spinal cord but did cause compression-related symptomatology and headache, which have not been reported in osteosynthesis wire migration to the thoracic region.

http://thejns.org/doi/abs/10.3171/2015.5.SPINE1596
\end{abstract}

KEY WORDS Kirschner wire; K-wire migration; spinal canal; cervical spine; spinal cord injury

$\mathrm{I}$ NTRAMEDULLARY osteosynthesis using Kirschner wires (K-wires) was introduced by Gordon Murray in 1940 as a surgical method to shorten the conservative treatment period. ${ }^{5}$ Since the method's introduction, it has suffered from migration complications; therefore, the method has been improved up to the present time, initially by using screw fixation in $1966 .{ }^{14}$ The migration of $\mathrm{K}$-wires is a rare but well-known and significant complication of this osteosynthesis method. Numerous cases of wire migration have been reported, with various migration pathways and specific symptomatic or asymptomatic presentations. ${ }^{1,10}$ Migration to the spinal canal is very rare, presumably because of the almost complete osseous protection of the canal by the vertebral column. ${ }^{7}$ In this report we present a case of symptomatic K-wire migration into the spinal canal without spinal cord injury.

\section{Case Report}

History and Examination

A 30-year-old male was brought to the Department of Neurosurgery at the Military Medical Academy in June 2014, complaining of bilateral numbness in the ulnar dermatomes and persistent headache. The patient stated that his symptoms began while he was lifting his child, as he experienced short-term pain in his back and numbness in all 4 extremities, followed by a spontaneous decrease in his symptoms before the examination. His medical history revealed that he had suffered a right clavicle fracture in a motorcycle accident 4 months earlier. As treatment for the fractured clavicle, fixation was performed with $2 \mathrm{~K}$-wires. In the follow-up period, one of the wires was removed and the other was left behind. 
The patient was conscious and oriented, with no vital functions compromised. A persistent headache, starting from the upper neck and spreading to the occipital and frontal region, was present with no cranial nerve symptoms. Neck flexion was followed by worsening of the headache. There was no papilledema or other signs of increased intracranial pressure. Numbness and sensory loss in the upper extremities in the distribution of the ulnar nerve were present, with no significant motor deficit. Cerebellar probes were negative. There was no urinary incontinence.

Radiography studies of the cervical spine showed a wire in the spinal canal (Fig. 1), penetrating the T-2 foramen and reaching the contralateral foramen of the same vertebra. This finding was confirmed by $\mathrm{CT}$, on which it was noted that the wire was positioned entirely in front of the spinal cord, with only a compressive effect on the structures in the spinal canal (Fig. 2). The lungs were not affected, as the wire was positioned in the muscles of the back.

\section{Operation}

The wire was surgically removed with the patient under general anesthesia. A skin incision was made at the right side of the back in the region of the transverse part of the trapezius muscle, $5 \mathrm{~cm}$ below the edge of the shoulder, medially and caudally oriented toward the spinal canal, and about $10 \mathrm{~cm}$ in length. Trapezius and supraspinatus muscle dissection was performed, and the wire tip was found in the intercostal muscle between the first 2 ribs protruding dorsally (Fig. 3). After identification of the tip, the K-wire was pulled out with forceps (Fig. 4). No sig-

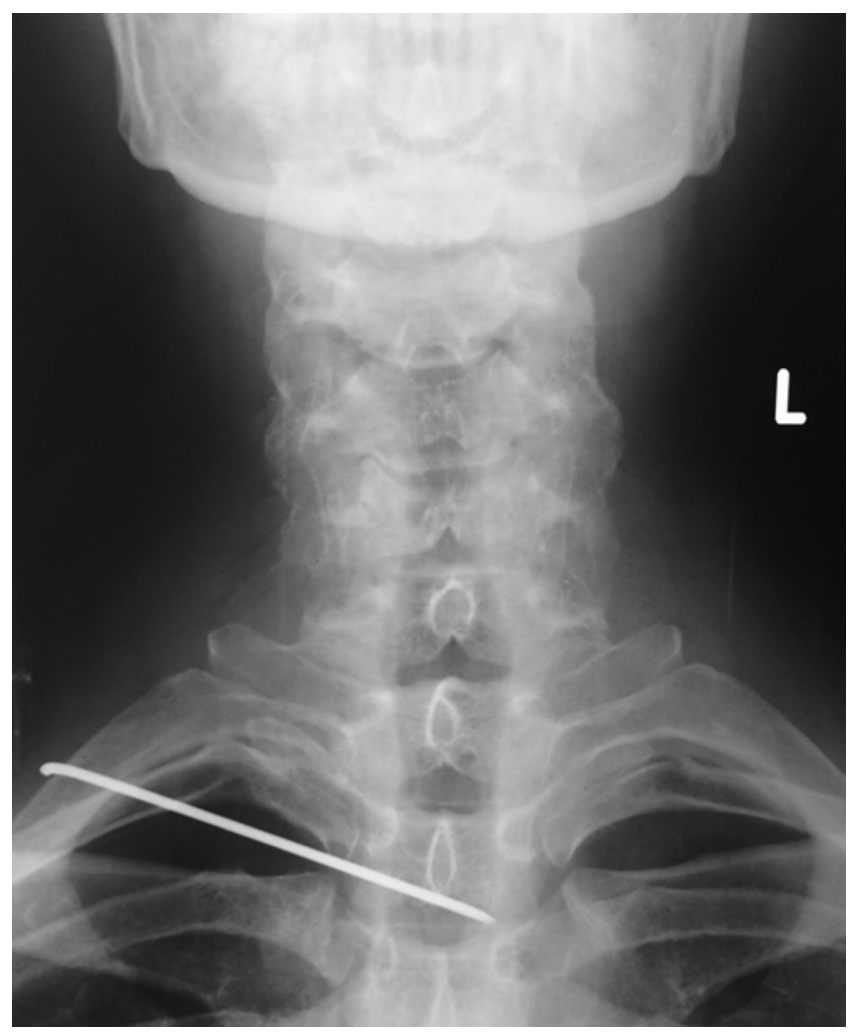

FIG. 1. Radiograph of the cervical spine showing a K-wire in the spinal canal at the level of the lower lid of the T-2 vertebra.

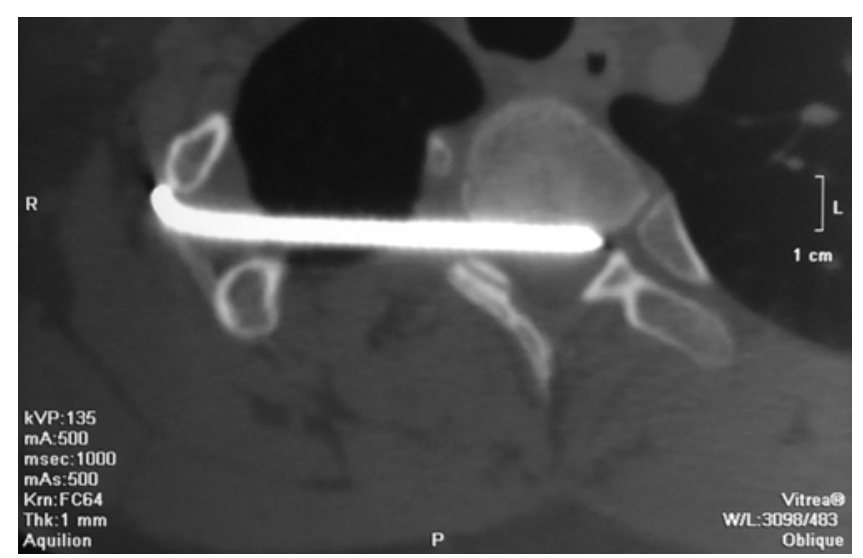

FIG. 2. Multislice CT showing the wire positioned entirely in front of the spinal cord, penetrating the right T-2 foramen and reaching the contralateral foramen of the same vertebra.

nificant bleeding or cerebrospinal fluid (CSF) leakage was noted. After routine hemostasis, wound closure was performed with simple sutures of muscles, fascia, and skin.

\section{Postoperative Course}

After surgery, all symptoms were instantaneously gone, and the patient felt no numbness in his arms or headache while recovering in the intensive care unit. During the 1-month follow-up, the patient reported sporadic headaches of lower intensity, which disappeared completely in the next 3 months.

\section{Discussion}

Migration of the wires used in shoulder bone fixation is a well-known complication that can be very dangerous and must therefore be adequately prevented. ${ }^{1,10}$ Migrations of K-wires into the spinal canal were initially reported in 1977 and 1986.,3 The present case features a man in whom 1 of the 2 implanted K-wires was left behind in the clavicle and had migrated into the spinal canal. Migration into the spinal canal without spinal cord injury usually presents with no neurological symptoms. ${ }^{2,4,8,11,17,20}$ In our

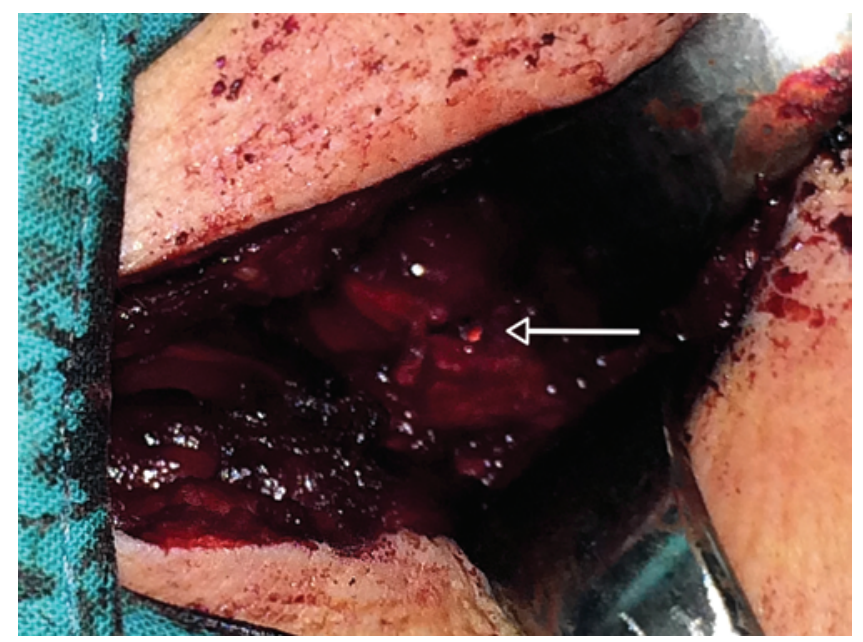

FIG. 3. The wire tip (arrow) was found in the muscle between the first and second rib. Figure is available in color online only. 


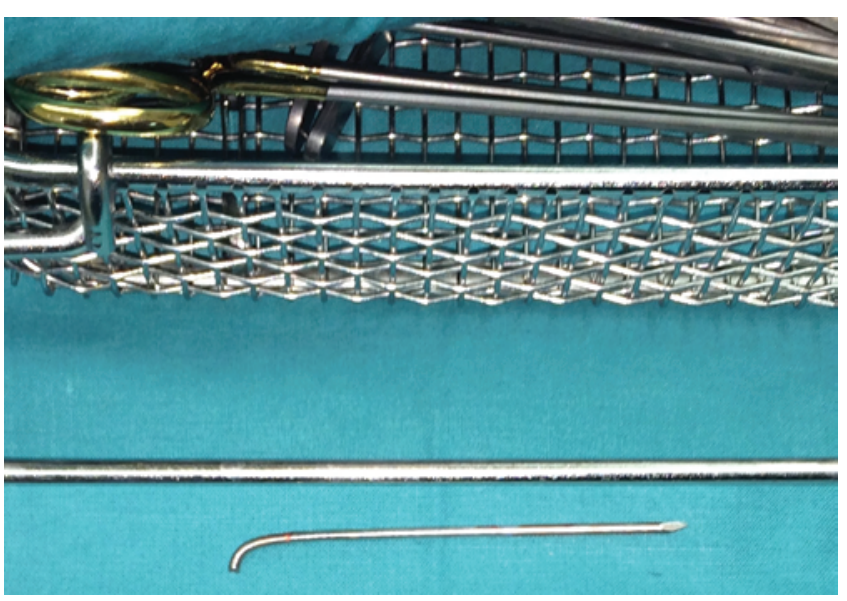

FIG. 4. The removed K-wire. Figure is available in color online only.

case the symptoms were present, although no signs of spinal cord injury were found, nor were they present during or after surgery.

The presence of a K-wire in the spinal canal caused bilateral numbness in the ulnar dermatomes as a result of spinal cord and spinal root compression, as well as headache. Both symptoms subsided after wire extraction. The exact cause of the headache remains uncertain, but meningeal irritation due to the presence of a foreign body ${ }^{12,13}$ is a plausible explanation, since there was no CSF leakage, which usually causes headache. ${ }^{18,19}$ Nevertheless, no other signs of meningeal irritation were present. Only 1 case reported in the literature describes a headache (together with pain and stiffness) in a patient with a foreign body in the spinal canal. ${ }^{12}$

Table 1 presents all previously reported cases of osteosynthesis material migration into the spinal canal. All patients were male, with ages ranging from 22 to 66 years. The wires migrated from the fixed clavicle in 7 cases, from the humeroscapular region in 1 case, ${ }^{20}$ and from an acromioclavicular joint fixation in 2 cases. ${ }^{8}, 15$ The point of entry into the spinal canal ranged from C5- $6{ }^{16}$ to T8 $-9,,^{20}$ most often at the C7-T1 $1^{2,3,6,15}$ and $\mathrm{T} 2-3^{4,8,9,11}$ levels. In the presented case, the penetration occurred at T2-3, which is the most common level. The migration was usually discovered in a period varying from 26 days ${ }^{20}$ to 2 years ${ }^{15}$ after insertion, with most cases diagnosed between the 2 nd and 4th month on routine follow-up radiography,2,8,111,16 due to an absence of any symptoms. After the material extraction, 1 patient recovered with persisting moderate lower limb hypesthesia ${ }^{4}$ and 1 with permanent sexual dysfunction,,$^{15}$ whereas other symptomatic patients attained a complete recovery in a maximum of 4 months, which was the case for our patient.

This case is unique for the presence of spinal cord compression symptoms and a headache without any injury to the spinal cord, which has never been reported in the thoracic region.

TABLE 1. Reported cases of osteosynthesis material migration into the spinal canal

\begin{tabular}{|c|c|c|c|c|c|c|c|c|}
\hline Authors \& Year & $\begin{array}{l}\text { Age } \\
\text { (yrs) }\end{array}$ & Sex & Initial Op & Symptoms & $\begin{array}{l}\text { Time From } \\
\text { Fixation to Dx } \\
\text { of Migration }\end{array}$ & Level & Spinal Cord Injury & Recovery \\
\hline $\begin{array}{l}\text { Hinzpeter \& Sartor, } \\
\qquad 1977^{\star}\end{array}$ & - & - & Clavicular fixation & $\begin{array}{l}\text { Optochiasmatic syn- } \\
\text { drome }\end{array}$ & $9 \mathrm{mos}$ & $\mathrm{C} 7-\mathrm{T} 1$ & - & - \\
\hline $\begin{array}{l}\text { Conzen \& Soll- } \\
\text { mann, 1986* }\end{array}$ & - & - & Clavicular fixation & - & - & $\mathrm{C} 7-\mathrm{T} 1$ & - & - \\
\hline Loncán et al., 1998 & 22 & M & Clavicular fixation & $\begin{array}{l}\text { Brown-Sequard syn- } \\
\text { drome }\end{array}$ & $2 \mathrm{mos}$ & T2-3 & Spinal cord pierced & Complete (4 mos) \\
\hline Regel et al., 2002 & 50 & M & Clavicular fixation & $\begin{array}{l}\text { Tetraparesis w/ loss of } \\
\text { bladder function }\end{array}$ & $3 \mathrm{mos}$ & C5-6 & - & Complete (1 day) \\
\hline $\begin{array}{l}\text { Pribán \& Toufar, } \\
2005\end{array}$ & 47 & M & $\begin{array}{r}\text { Acromioclavicular } \\
\text { osteosynthesis }\end{array}$ & $\begin{array}{l}\text { Severe paraparesis of } \\
\text { lower limbs }\end{array}$ & $2 \mathrm{yrs}$ & $\mathrm{C} 7-\mathrm{T} 1$ & $\begin{array}{l}\text { Transverse penetration } \\
\text { through spinal cord }\end{array}$ & $\begin{array}{c}\text { Permanent sexual } \\
\text { dysfunction }\end{array}$ \\
\hline $\begin{array}{l}\text { Fransen et al., } \\
2007\end{array}$ & 30 & M & Clavicular fixation & $\begin{array}{l}\text { Bilat pyramidal syn- } \\
\text { drome, paraparesis, \& } \\
\text { hypesthesia under a } \\
\text { T-4 level }\end{array}$ & $1 \mathrm{yr}$ & T2-3 & $\begin{array}{l}\text { Perforation of spinal } \\
\text { cord w/ a transverse } \\
\text { trajectory }\end{array}$ & $\begin{array}{l}\text { Moderate hypes- } \\
\text { thesia of lower } \\
\text { limbs ( } 6 \text { wks) }\end{array}$ \\
\hline Bennis et al., 2008 & 57 & M & Clavicular fixation & Asymptomatic & 4 mos & $\mathrm{C} 7-\mathrm{T} 1$ & - & - \\
\hline $\begin{array}{l}\text { Mamane et al., } \\
2009\end{array}$ & 34 & M & Clavicular fixation & $\begin{array}{l}\text { No neurological deficit, } \\
\text { acute respiratory } \\
\text { failure related to a } \\
\text { pneumothorax }\end{array}$ & $2 \mathrm{mos}$ & T2-3 & - & - \\
\hline Was et al., 2010 & 66 & M & $\begin{array}{l}\text { Humeroscapular } \\
\text { fixation }\end{array}$ & Asymptomatic & 26 days & T8-9 & - & - \\
\hline Li et al., 2013 & 35 & M & $\begin{array}{c}\text { Acromioclavicular } \\
\text { osteosynthesis }\end{array}$ & Asymptomatic & $2 \mathrm{mos}$ & $\mathrm{T} 2-3$ & - & - \\
\hline
\end{tabular}

Dx = diagnosis; $-=$ data missing.

* Articles in German language. Full text not available through any of the academic databases. Some details possibly missing. 


\section{Conclusions}

Although considered routine, the procedure for shoulder bone fixation should not be underestimated or taken lightly given its simplicity. The migration of fixation material may, in some cases, be fatal or can lead to permanent neurological deficits. ${ }^{10}$ The use of terminally threaded pins or pins bent at the end is advised. Proper immobilization of the arm and shoulder should last long enough to secure the best possible recovery without complications (migration in particular), and radiographic and clinical followups should always be performed. If there is no possibility of removing the fixation material, even more attention is needed until further movement of the material can be completely ruled out.

\section{References}

1. Ballas R, Bonnel F: Endopelvic migration of a sternoclavicular K-wire. Case report and review of literature. Orthop Traumatol Surg Res 98:118-121, 2012

2. Bennis S, Scarone P, Lepeintre JF, Puyo P, Aldea S, Gaillard S: Asymptomatic spinal canal migration of clavicular K-wire at the cervicothoracic junction. Orthopedics 31:31, 2008

3. Conzen M, Sollmann H: [Displacement of materials in the cervical spinal canal following clavicular fixation as a late complication.] Unfallchirurg 89:47-48, 1986 (Ger)

4. Fransen P, Bourgeois S, Rommens J: Kirschner wire migration causing spinal cord injury one year after internal fixation of a clavicle fracture. Acta Orthop Belg 73:390-392, 2007

5. Geckeler EO: Fractures of the clavicle in adults; Kirschner wire fixation (Murray method). Am J Surg 81:333-335, 1951

6. Hinzpeter T, Sartor K: [The problem of material migration following osteosynthesis: penetration of a Kirschner wire into the spinal canal.] Rofo 127:493-494, 1977 (Ger)

7. Leppilahti J, Jalovaara P: Migration of Kirschner wires following fixation of the clavicle-a report of 2 cases. Acta Orthop Scand 70:517-519, 1999

8. Li Y, Wang B, Lv G, Xiong G, Liu W: Video-assisted thoracoscopic surgery for migration of a Kirschner wire in the spinal canal: a case report and literature review. Turk Neurosurg 23:803-806, 2013

9. Loncán LI, Sempere DF, Ajuria JE: Brown-Sequard syndrome caused by a Kirschner wire as a complication of clavicular osteosynthesis. Spinal Cord 36:797-799, 1998

10. Lyons FA, Rockwood CA Jr: Migration of pins used in operations on the shoulder. J Bone Joint Surg Am 72:12621267,1990
11. Mamane W, Breitel D, Lenoir T, Guigui P: [Spinal migration of a Kirschner wire after surgery for clavicular nonunion. A case report and review of the literature.] Chir Main 28:367369, 2009 (Fr)

12. Miyazaki Y, Inaba K: [Transfixion of cervical cord by a glass fragment-report of a case (author's transl).] No Shinkei Geka 4:799-803, 1976 (Jpn)

13. Pelin Z, Kaner T: Intracranial metallic foreign bodies in a man with a headache. Neurol Int 4:e18, 2012

14. Perry BF: An improved clavicle pin. Am J Surg 112:142144, 1966

15. Pribán V, Toufar P: [A spinal cord injury caused by a migrating Kirschner wire following osteosynthesis of the clavicle: a case review.] Rozhl Chir 84:373-375, 2005 (Czech)

16. Regel JP, Pospiech J, Aalders TA, Ruchholtz S: Intraspinal migration of a Kirschner wire 3 months after clavicular fracture fixation. Neurosurg Rev 25:110-112, 2002

17. Tsai CH, Hsu HC, Huan CY, Chen HT, Fong YC: Late migration of threaded wire (Schanz screw) from right distal clavicle to the cervical spine. J Chin Med Assoc 72:48-51, 2009

18. Ulloth JE, Haines SJ: Acupuncture needles causing lumbar cerebrospinal fluid fistula. Case report. J Neurosurg Spine 6:567-569, 2007

19. Wang YF, Fuh JL, Lirng JF, Chen SP, Hseu SS, Wu JC, et al: Cerebrospinal fluid leakage and headache after lumbar puncture: a prospective non-invasive imaging study. Brain 138:1492-1498, 2015

20. Was MT, Kurowski K, Francuz I: Migration of Kirschner wire into the spinal canal as complication of inveterate shoulder luxation treatment - case study. Ortop Traumatol Rehabil 12:370-375, 2010

\section{Disclosure}

The authors report no conflict of interest concerning the materials or methods used in this study or the findings specified in this paper.

\section{Author Contributions}

Conception and design: Lepić, Minić. Acquisition of data: Minić. Analysis and interpretation of data: Lepić, Mandić-Rajčević. Drafting the article: Lepić, Novaković, Mandić-Rajčević. Critically revising the article: Minić, Mandić-Rajčević. Reviewed submitted version of manuscript: Mandić-Rajčević. Study supervision: Mandić-Rajčević.

\section{Correspondence}

Milan Lepić, Military Medical Academy, Crnotravska 11G, Belgrade 11000, Serbia. email: milanlepic@gmail.com. 